\title{
Modern School, Basis for Development of Interpersonal and Intercultural Competence
}

\author{
Svetlana Pandiloska Grncharovska ${ }^{1}$, Fadbi Osmani $^{2}$, Gordana Stankovska ${ }^{3}$ \\ ${ }^{\prime}$ (Department of Pedagogy, State University of Tetovo,, Macedonia) \\ ${ }^{2}$ (Department of Pedagogy, State University of Tetovo, Macedonia) \\ ${ }^{3}$ (Department of Psychology, State University of Tetovo, Macedonia)
}

\begin{abstract}
The development of interpersonal competence among students means increasing of their abilities for a comprehensive personal and professional development Within the frames of traditional school children learn more about interpersonal relations during the breaks and leisure activities than during classes. The principal aim of the intercultural education is to promote and to develop the capacities of interaction and communication between pupils and the world that rounds them. If we don't want to create impoverished uniformity in our schools based on segregation and elitism, the development of intercultural competence should be one of the main goals of all schools in today's society. The skills for constructive communication in diverse environments, expressing and understanding of different views, negotiating with ability to create trust and feeling of empathy are the core of this competence
\end{abstract}

Key words: school, students, interpersonal competence, intercultural competence

\section{THE IMPORTANCE OF THE INTERPERSONAL COMPETENCE}

The Interpersonal competence is a competence that embraces all forms of behavior that needs to be overcome in order one individual to be enabled effectively and constructively to participate in the social life and to resolve problems when needed. This competence includes: the development of critical and self-critical abilities, teamwork, ability to work in an interdisciplinary team, the ability to communicate with experts from other areas, respect for diversity and multiculturalism, the ability to work in an international context ethical commitment as well as development of interpersonal skills that are essential for efficient interaction between two or more people in the public and private sphere (Blažinić, 2010).The development of interpersonal competence among students means increasing of their abilities for a comprehensive personal and professional development. The Interpersonal competence does not only enable better understand of the present, but it also enables us as individuals to succeed better in the modern world and to achieve more constructive and positive changes in our society, as well. From the above written we can say that, the competence involves a process of personal development that could have a broader impact further on the society. Even from the time of Jan Amos Comenius it was considered that the main task of the teacher is to be better than textbook i.e. "to put lectures inside the students' heads". This one-sidedness lasted until the end of the twentieth century (Suzić, 2006). Namely, if the teacher is concerned only with the curricula in order to transfer it to students, than the curricula and not the students are the subject of the teaching process because the teacher is interested only with the curricula. If the students are involved in the curricula (contents), then we talk about learning. In the relation students-curricula we will come across learning didactics, training students to learn how to learn, while in the relation teacher-student we need "didactics of the interpersonal relationships". Howard Gardner believes that interpersonal competences are among the seven abilities( competences) in general and under interpersonal competences he means ten skills: giving feedback, premonitions of others' feelings, cooperative learning, communication "face to face", capability of understanding, division of labor, art of collaboration, feedback application, feeling of empathy, group projects. (Suzić, 2006). Within the frames of traditional school children learn more about interpersonal relations during the breaks and leisure activities than during classes. The essence of interpersonal learning is engagement of the child's social motives. Social support in traditional school is accomplished more behind the scenes of permissible behavior than formal, such as whispering while the student gives oral answers or while using corresponding tabs for rewriting. The traditional frontal teaching instead of social support usually develops envy directed from the weaker towards the better students as well as a feeling of inferiority. From the above written, one question arises and that is, what will the educational solutions be after nine or thirteen years of schooling in the traditional school where the students only sit, listen, repeat and carry out the orders given by the teacher, and what will the educational solutions be in schools where every child, every day at least once works interactively, gives presentations of the realized and experiences social promotion? 
It is clear that the traditional school will result in submission and obedience and produce slaves to the new world order, while the school in where partnership is promoted will produce partners.(Suzić, 2006).

\section{The Importance Of The Intercultural Competence}

The realization of the intercultural competence cannot be carried out through the contents of one or several school subjects but it is included within the frames of the overall educational activity in the formal as well as in the informal education.

The intercultural competence can help us understand the complexity of the modern world through deeper (thorough) understanding of other people and ourselves.

The intercultural principles concentrate on: openness to the other, active respect for diversity, mutual comprehension, active tolerance and validating the cultures present, providing equality of opportunities and fighting discrimination. In this context, according to Ouellet (1991), intercultural education can be designed to promote and to develop:

- A larger capacity of communication between people from different cultures,

- A more flexible attitude to the context of cultural diversity in the society,

- A better capacity of participation in social interaction with people from a different cultural origin and recognition of the common heritage of humanity

The principal aim of the intercultural education is to promote and to develop the capacities of interaction and communication between pupils and the world that surrounds them.

Intercultural education places the other at the centre of relations. It encourages a continuous questioning of presuppositions or things we normally take for granted and encourages a constant opening to the unknown and the not understood. In a process of interaction and mutual discovery every human being can fulfil himself/herself personally, socially and globally. The intercultural education, in this case, has a role to promote empowerment of pupils' capacities and enable them to function fully within the society.

If we don't want to create impoverished uniformity in our schools based on segregation and elitism, the development of intercultural competence should be one of the main goals of all schools in today's society.

Building trust in order to achieve the openness which is necessary for the mutual process, is the basis for the intercultural learning. The sense of security is a prerequisite for the ability to exchange different views, beliefs and feelings in order to reach mutual understanding and acceptance. This means that each person should be given some space to express, to take into account all the experiences and talents and diverse needs and expectations. The mutual trust is also presented through mutual respect and sincerity in mutual exchange.

The intercultural learning places "the other" at the heart of understanding. It starts through dialogue, but yet is a step further. The intercultural learning is an experience which is more intense and includes all the senses and learning levels, knowledge, emotions and behavior. In this context it can be emphasized that one intercutural competent individual possesses the following features: Capacity for mediation, interpretation, critical and analytical understanding of the personal and the culture of the other as well and intercultural communication

- Capacity "to see", understand and accept the relation between different cultures,

- Cognitive and emotional dimension in the interpersonal relationships

Language as a part of the culture is the main factor in the intercultural communication, but in the same time because of its narrowness is also a factor of misunderstanding. Due to this, the language must not have a dominant role especially when taking into consideration different linguistic knowledge and skills, but it has to be only one of the means of communication. Also, all the other signs should be taken into consideration such as the body language. If we pay attention to how different cultures perceive time, space, personal and social relations it becomes clear that the opportunity for conflict is at the heart of intercultural learning and therefore it should be explored and displayed.Conflicts are inevitable elements of our everyday lives, either constructive or destructive. For them there is no universal definition, understanding and conflict resolution is more important than defining (Petroska-Beshka, 1995). Without conflicts there is no personal and social change. Potential conflict should be used, not be overlooked.

\section{CONCLUSION}

The development of interpersonal and intercultural competence embraces all the forms of behavior which enable students efficiently and constructively to be included in their social and later in their work life, especially in the existing diverse societies and to resolve conflicts where necessary. Personal and social good requires an understanding of how people can ensure optimum physical and mental health as wealth for themselves and their family and knowledge of how a healthy lifestyle can contribute to this. For a successful interpersonal and intercultural participation it is necessary to understand the behavioral rules and the generally accepted ways in different societies and environments and to be aware for the basic concepts related to: individuals, groups, working organizations, gender equality, society and culture. Understanding the multi- 
cultural and socio-economic dimension of European society and how national cultural identity interacts with the European identity is essential.The skills for constructive communication in diverse environments, expressing and understanding of different views, negotiating with ability to create trust and feeling of empathy are the core of this competenceWithin this frames the students should be enabled to deal with the stress and frustrations and to express them in more constructive way as well as to make a difference between the personal and professional sphere. The students should also show interest for the socially-economic development, diverse values and the respect towards others and to be ready to overcome prejudices and to make a compromise, as well (Commission of the European Communities, 2005).

\section{REFERENCES}

[1] Blažinić, B. (2010). EQF and development of key competence for a lifelong learning: Interpersonal competence and conflict resolution (management), Institute for quality and development of human potential, Zagreb, p.13.

[2] Lalović, Z. (2009). Learning / teaching methods, Our School, IVPE Cetinje: Institute for School Affairs. p. 30.

[3] Petroska-Beska, V. (1995). Conflicts - what are conflicts and how to manage them, Skopje: Faculty of Philosophy, p.3-8.

[4] Suzić, N. (2006). Didactics at the crossroads of centuries. Didactic Links, Journal of Educational Theory and Practice no. 39. 7-17,p-7 